Gut, 1971, 12, 139-144

\title{
Copper kinetics in liver disease
}

\author{
R. A. SMALLWOOD, B. McILVEEN, V. M. ROSENOER, AND S. SHERLOCK
}

From the Medical Unit and Department of Medical Physics, Royal Free Hospital, London

SUMMARY The plasma clearance and the liver uptake of intravenously administered ${ }^{64} \mathrm{Cu}$ were significantly impaired in four patients with Wilson's disease. These defects were unlikely to be simply expressions of the high liver copper concentration as the plasma clearance and hepatic uptake of ${ }^{64} \mathrm{Cu}$ were normal in four patients with primary biliary cirrhosis, in whom the liver copper concentration was raised to a degree comparable to that in Wilson's disease. The normal liver uptake and plasma clearance of ${ }^{64} \mathrm{Cu}$ in three patients with other forms of hepatocellular disease suggest that impaired liver cell function does not have a significant effect. The precise nature of the defect in copper transport in Wilson's disease remains to be elucidated; it is possible that delayed uptake of copper by the hepatic lysosomes may account for the toxic effects of the metal.

In normal subjects radioactive copper injected intravenously in trace amounts is cleared very rapidly from the plasma-almost entirely by the liver. In patients with Wilson's disease (hepatolenticular degeneration), the plasma clearance of radiocopper is measurably slower and the hepatic uptake appears to be impaired (Osborn and Walshe, 1961 ; Sass-Kortsak, Glatt, Cherniak, and Cederlund, 1961). Following prolonged penicillamine therapy which reduces the hepatic copper concentration in these patients the liver uptake of copper returns towards normal, and it has been proposed that the impaired liver copper uptake in Wilson's disease is primarily an expression of the high liver copper level (Osborn and Walshe, 1967).

If this hypothesis were true, it would be expected that patients with prolonged biliary obstruction, in whom the liver copper concentration is raised to a degree comparable to that in Wilson's disease (Smallwood, Williams, Rosenoer, and Sherlock, 1968), would handle intravenously injected radiocopper in the same way as patients with Wilson's disease. In the present study, the plasma disappearance and liver uptake of ${ }^{64} \mathrm{Cu}$ in patients with Wilson's disease were compared with those of patients with primary biliary cirrhosis.

\section{Methods}

The informed consent of all subjects used in this

Received for publication 30 September 1970. investigation was obtained. Radiocopper studies were performed on four patients with Wilson's disease and four patients with primary biliary cirrhosis (Table I). Two control groups were also studied: three patients with hepatocellular disease and three normal subjects. The patients with Wilson's disease had been on penicillamine therapy (0.9-1.2 $\mathrm{g}$ daily) for four to eight years, and this was temporarily stopped $48-72$ hours before each study. Three had had neurological manifestations only and the fourth had well compensated cirrhosis. In the patients with primary biliary cirrhosis and those with hepatocellular disease there was no evidence of ascites, a bleeding tendency, or portal systemic encephalopathy. Normal subjects comprised one woman and two men convalescing after minor orthopaedic procedures, all with no evidence of liver dysfunction.

\section{EXPERIMENTAL DESIGN}

At time zero, an accurately weighed dose (14.5$34.0 \mu \mathrm{g})$ of ${ }^{64} \mathrm{CuCl}_{2}(100 \mu \mathrm{Ci})$ was injected into the antecubital vein. The radiation dose of $100 \mu \mathrm{Ci}$ of ${ }^{64} \mathrm{Cu}$ (which decays with a half-life of $12 \cdot 8$ hours by electron capture, emitting a positron) is very small. Assuming total retention of the isotope in the liver, $100 \mu \mathrm{Ci}$ would give approximately 0.4 rems. Multiple venous blood samples were taken over the next six hours, and total output of urine was collected over the same period. To assess liver uptake of radiocopper, counting was carried out over the surface of the liver using a collimated 
probe at regular intervals over 30 hours. Care was taken to ensure that the collimator was positioned in precisely the same way for each reading. A sealed counting standard, made up of a known aliquot of the injected dose, was counted before and after each reading to allow correction for any fluctuations in counting efficiency.

There were no sites of accumulation of radioactivity other than the liver detectable by surface counting in any of the four groups of patients.

\section{ANALYSES}

In those subjects who underwent liver biopsy as part of their clinical management, the liver copper content was measured by neutron activation analysis (Todd, Thorpe, and Rosenoer, 1967). Plasma copper levels were measured by atomic absorption spectrophotometry, and plasma caeruloplasmin levels by immunodiffusion. Assuming 8 copper atoms per molecule of caeruloplasmin (MW 160,000 daltons), the amounts of caeruloplasmin-bound and 'free', ie, that bound to albumin and amino acids, copper in plasma could be calculated. Plasma samples $(4 \mathrm{ml})$ were counted in a Packard Auto Gamma spectrometer against a standard prepared from a weighed aliquot of the injected dose.

Plasma volumes were measured using 1-2 $\mu \mathrm{Ci}$ of ${ }^{131}$ I-human serum albumin, uptake of ${ }^{131}$ I by the thyroid being prevented by the administration of potassium iodide ( $200 \mathrm{mg}$ daily) for two weeks.

To separate caeruloplasmin-bound ${ }^{64} \mathrm{Cu}$ from 'free' ${ }^{64} \mathrm{Cu}$, the following procedure was carried out. An equal volume $(4 \mathrm{ml})$ of $2 \%$ diethylenetriaminepenta-acetic acid (DTPA), a copper chelating agent, was added to each plasma sample. Globulins were precipitated by adding an equal volume of saturated ammonium sulphate. After standing for one hour, samples were centrifuged at $13,000 \mathrm{~g}$ for 20 minutes, and the supernatant decanted. The precipitate was washed three times with $50 \%$ ammonium sulphate, redissolved in $4 \mathrm{M}$ urea, and again counted against the standard. The initial count gave the total plasma ${ }^{64} \mathrm{Cu}$, the final count the caeruloplasmin bound ${ }^{64} \mathrm{Cu}$. The 'free' ${ }^{64} \mathrm{Cu}$ was obtained by difference. Preliminary studies in which ${ }^{64} \mathrm{Cu}$ was added to plasma samples showed that less than $5 \%$ of the radiocopper (all 'free' in this case) was recovered in the washed precipitate. In patients with Wilson's disease, no activity was detected in the ammonium sulphate precipitate.

The urine output after six hours was measured, and a $4 \mathrm{ml}$ aliquot counted with the plasma samples. As the radioactive half-life of ${ }^{64} \mathrm{Cu}$ is short $(12.8$ hours), the time of counting of each sample was carefully noted and appropriate corrections were made for radioactive decay.

\section{Results}

The liver copper levels (Table I) determined in the patients with primary biliary cirrhosis ranged from 367 to $714 \mu \mathrm{g} / \mathrm{g}$ dry liver, concentrations well above the lower limit $(250 \mu \mathrm{g} / \mathrm{g}$ dry liver) of the levels found in Wilson's disease (Smallwood et al, 1968; Sternlieb and Scheinberg, 1968). In one of the patients with Wilson's disease treated with penicillamine for four years, the liver copper was $250 \mu \mathrm{g} / \mathrm{g}$ dry liver. No levels were obtained in the other three cases. The three patients with hepatocellular disease had normal or near normal liver copper concentrations (43-70 $\mu \mathrm{g} / \mathrm{g}$ dry liver).

The plasma 'free' copper concentrations in the two control groups and in the four patients with Wilson's disease were within the normal range of

\begin{tabular}{|c|c|c|c|c|c|c|c|c|}
\hline \multicolumn{2}{|c|}{ Subject } & Age (yr) & $\operatorname{Sex}$ & Diagnosis & $\begin{array}{l}\text { Liver Copper Concentration } \\
(\mu g / g \text { dry weight })\end{array}$ & Dose " ${ }^{\circ C} \mathrm{Cu}(\mu \mathrm{g})$ & Liver Function Tests & $\begin{array}{l}\text { Plasma Volume } \\
(\mathrm{ml})\end{array}$ \\
\hline 1 & R.S. ${ }^{1}$ & 34 & $\mathbf{M}$ & Wilson's disease & 250 & $18 \cdot 0$ & Normal & 3,004 \\
\hline 2 & M.L. ${ }^{1}$ & 32 & $\mathbf{F}$ & Wilson's disease & - & $19 \cdot 6$ & Normal & 3,005 \\
\hline 3 & J.A. ${ }^{1}$ & 30 & $\mathbf{F}$ & Wilson's disease & - & 13.6 & Normal & 2,585 \\
\hline 4 & J.F.'2 & 21 & $\mathbf{F}$ & Wilson's disease & - & $21 \cdot 2$ & Normal & 2,553 \\
\hline 5 & A.R. & 48 & $\mathbf{F}$ & Primary biliary cirrhosis & 714 & 15.8 & bilirubin & 2,439 \\
\hline 6 & J.E. & 53 & $\mathbf{F}$ & Primary biliary cirrhosis & 410 & raised & alk. phos. & 2,438 \\
\hline 7 & D.C. & 60 & $\mathbf{F}$ & Primary biliary cirrhosis & 367 & $31 \cdot 0$ & cholesterol & 3,279 \\
\hline 8 & M.D. & 56 & $\mathbf{F}$ & Primary biliary cirrhosis & 375 & $27 \cdot 4$ & & 3,243 \\
\hline 9 & G.D. & 47 & $\mathbf{M}$ & Cirrhosis & 56 & $34 \cdot 0$ & BSP retention & 3,188 \\
\hline 10 & J.H. & 42 & $\mathbf{M}$ & Cirrhosis & 70 & 14.5 & BSP retention & 2,625 \\
\hline 11 & F.M. & 30 & $\mathbf{F}$ & Hepatitis & 43 & $15 \cdot 3$ & bilirubin & \\
\hline & & & & & & & (SGOT & 2,350 \\
\hline 12 & P.B. & 22 & $\mathbf{M}$ & Hallux valgus & - & 33.8 & Normal & 2,774 \\
\hline 13 & P.S. & 27 & $\mathbf{M}$ & Menisectomy & - & 16.9 & Normal & 3,223 \\
\hline 14 & J.K. & 50 & $\mathbf{F}$ & Hallux valgus & - & $24 \cdot 0$ & Normal & 2,350 \\
\hline
\end{tabular}

Table I Details of the subjects in the present series

${ }^{1}$ Patients 1, 2, and 3 had neurological manifestations and no clinical evidence of liver disease. 'Patient 4 had well compensated cirrhosis. 


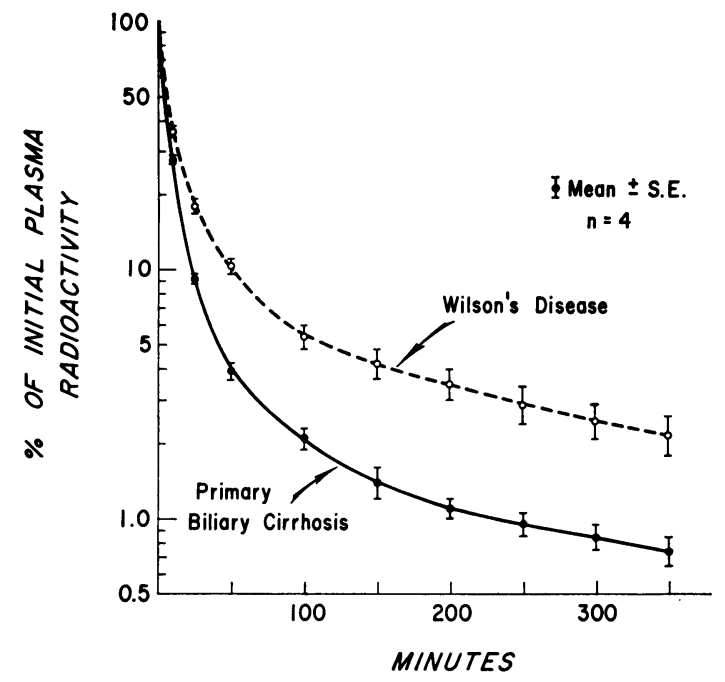

Fig. 1. Plasma disappearance curves of intravenously injected ${ }^{64} \mathrm{Cu}$ in patients with primary biliary cirrhosis and in patients with Wilson's disease.

5 to $10 \mu \mathrm{g} / 100 \mathrm{ml}$. However, the 'free' copper concentration in the patients with primary biliary cirrhosis was significantly raised in all but one patient, the values ranging from 5 to $99 \mu \mathrm{g} / 100 \mathrm{ml}$ with a median concentration of $38 \mu \mathrm{g} / 100 \mathrm{ml}$. The total plasma copper concentration in these patients ranged from 140 to $226 \mu \mathrm{g} / 100 \mathrm{ml}$; the caeruloplasmin concentration ranged from 32.9 to 50.2 $\mathrm{mg} / 100 \mathrm{ml}$. The patient with normal 'free' copper concentration had a total plasma copper concentration of $173 \mu / 100 \mathrm{mlg}$ and a caeruloplasmin concentration of $50.2 \mathrm{mg} / 100 \mathrm{ml}$.

Figure 1 compares the plasma disappearance of intravenously injected ${ }^{64} \mathrm{Cu}$ in primary biliary cirrhosis and in Wilson's disease. There is a clear difference between the disappearance rates of radiocopper in the two groups. The plasma radioactivity fell at a significantly faster rate in primary biliary cirrhosis, such that levels reached $10 \%$ of

\begin{tabular}{llll}
\hline Condition & $\begin{array}{c}\text { No. of } \\
\text { Studies }\end{array}$ & $\begin{array}{l}\text { Time to Reach } \\
\text { 10\% of Initial } \\
\text { Plasma Radio- } \\
\text { activity (min) }\end{array}$ & $\begin{array}{l}\text { Liver Copper } \\
\text { Concentration } \\
\text { ( } \mu \mathrm{g} \text { Cu/g dry } \\
\text { liver) }\end{array}$ \\
\hline Wilson's disease & 4 & $49 \cdot 3 \pm 1.4^{1}$ & $250^{2}$ \\
Primary biliary cirrhosis & 4 & $22 \cdot 5 \pm 0.36$ & $467 \pm 83$ \\
Hepatocellular disease & 3 & $21 \cdot 0 \pm 1.4$ & $56 \pm 9$ \\
Normal & 3 & $22.0 \pm 1.4$ & - \\
\hline
\end{tabular}

Table II Plasma disappearance of ${ }^{64} \mathrm{Cu}$

${ }^{1}$ Mean \pm SE.

'Estimate in one patient: time to reach $10 \%$ of initial plasma radioactivity was 48 minutes. their initial value 26.8 minutes earlier than in Wilson's disease $(\mathrm{P}<0.01)$. No significant difference was found when primary biliary cirrhosis was compared with the two control groups (Table II). The rate of disappearance of radiocopper from plasma did not correlate with the liver copper concentration.

Very little of the administered radiolabel was excreted in urine in the first six hours (Table III). Although the mean six-hour ${ }^{64} \mathrm{Cu}$ excretion was higher in Wilson's disease, there was no significant difference from the other groups. Variations in urinary excretion of radiolabel, therefore, are unlikely

\begin{tabular}{lll}
\hline Condition & No. of Studies & $\begin{array}{l}\% \text { Dose Excreted in the } \\
\text { First Six Hours }\end{array}$ \\
\hline Wilson disease & 4 & $1 \cdot 9 \pm 1 \cdot 0$ \\
Primary biliary cirrhosis & 4 & $0 \cdot 7 \pm 0 \cdot 1$ \\
Hepatocellular disease & 3 & $0 \cdot 3 \pm 0 \cdot 1$ \\
Normal & 3 & $0 \cdot 2 \pm 0 \cdot 1$ \\
\hline
\end{tabular}

Table III Urinary excretion of ${ }^{64} \mathrm{Cu}$

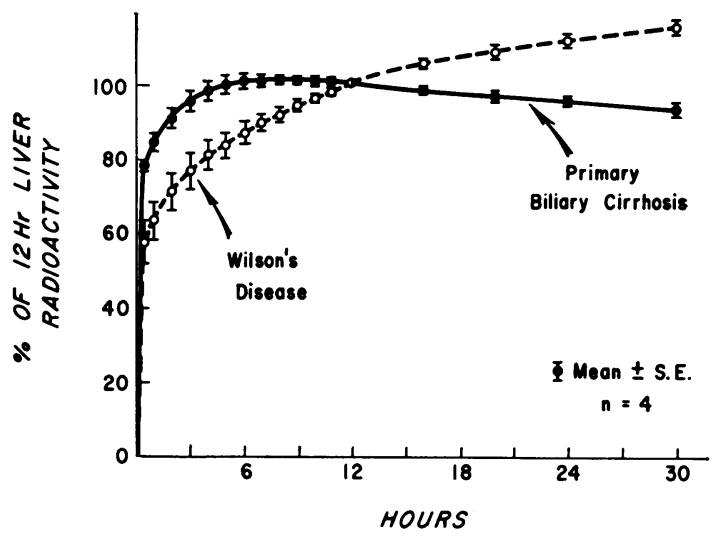

Fig. 2. Liver radioactivity in patients with primary biliary cirrhosis and in those with Wilson's disease following intravenously administered ${ }^{64} \mathrm{Cu}$. The curves have been normalized by expressing the collimated counts over the liver at any time as a percentage of the 12-hour counts.

to account for the observed differences in plasma disappearance rates of ${ }^{64} \mathrm{Cu}$.

Figure 2 compares the changing patterns of liver radioactivity in primary biliary cirrhosis and Wilson's disease in the 30 hours following the intravenous injection of radiocopper. To allow a direct comparison, the curves have been normalized 
by expressing the counts over the liver at any time as a percentage of the 12-hour counts. At this point, all patients other than those with Wilson's disease had achieved maximal levels of ${ }^{64} \mathrm{Cu}$ in the liver. There was a striking difference between the two groups of patients. In primary biliary cirrhosis the initial uptake of radiocopper was faster, a plateau was attained, and after 12 hours the level of radioactivity slowly fell to $90 \%$ of the maximal level by 30 hours. In Wilson's disease the uptake was more gradual and liver radioactivity continued to rise throughout the $\mathbf{3 0}$ hours without achieving a plateau. The pattern of liver uptake of ${ }^{64} \mathrm{Cu}$ in hepatocellular disease and in normal subjects was identical to that seen in primary biliary cirrhosis (Table IV); the initial rate of uptake in Wilson's disease was significantly slower $(\mathrm{P}<0.01)$.

\begin{tabular}{|c|c|c|c|}
\hline \multirow[t]{2}{*}{ Condition } & \multirow{2}{*}{$\begin{array}{l}\text { No. of } \\
\text { Studies }\end{array}$} & \multicolumn{2}{|c|}{ Percentage of 12-hour Liver Uptake } \\
\hline & & At One Hour & At Four Hours \\
\hline $\begin{array}{l}\text { Wilson's disease } \\
\text { Primary biliary cirrhosis } \\
\text { Hepatocellular disease } \\
\text { Normal }\end{array}$ & $\begin{array}{l}4 \\
4 \\
3\end{array}$ & $\begin{array}{l}63 \cdot 3 \pm 5 \cdot 5 \\
84 \cdot 8 \pm 2 \cdot 2 \\
85 \cdot 8 \pm 2 \cdot 2 \\
79 \cdot 3 \pm 4 \cdot 7\end{array}$ & $\begin{array}{l}80 \cdot 8 \pm 4 \cdot 1 \\
98 \cdot 1 \pm 2 \cdot 5 \\
97 \cdot 6 \pm 2 \cdot 1 \\
94 \cdot 2 \pm 2 \cdot 6\end{array}$ \\
\hline
\end{tabular}

Table IV Liver uptake of ${ }^{64} \mathrm{Cu}$

\section{Discussion}

Wilson's disease is now generally regarded as the clinical manifestation of a disturbance of copper metabolism, in which large amounts of copper accumulate in body tissues. The half-time for copper in Wilson's disease has been calculated from ${ }^{64} \mathrm{Cu}$ whole body counting data to be 97.0 days as compared with $17 \cdot 1$ days in normal subjects (Hamamoto, Tauxe, Novak, and Goldstein, 1968) and from ${ }^{67} \mathrm{Cu}$ whole body counting data to be 140 days compared with 26 days in normal subjects (O'Reilly, Webber, Pollycove, and Shipley, 1969). The organs mainly affected clinically and pathologically - the liver, brain, and kidneys-are those exhibiting the highest tissue copper concentrations (Cumings, 1959). Moreover, treatment directed at removing copper from the body leads to marked clinical improvement (Walshe, 1963).

Attempts to elucidate the basic metabolic defect which leads to the excessive retention of copper in the body have so far been unsuccessful. Whether the defect resides in the proximal absorptive mechanism, the distal excretory mechanism, or in the tissues themselves has not been adequately clarified. Studies with caeruloplasmin over the past two decades, whilst providing an enormous amount of clinically useful data, have not provided a unified concept of all the abnormalities observed in this disease (Sass-Kortsak, 1965).

Radiocopper studies utilizing both counting of plasma samples and collimated counting over the liver have enhanced our understanding of copper metabolism and have revealed that, after intravenous injection of ${ }^{84} \mathrm{Cu}$ into normal subjects, the tracer disappears very rapidly from the plasma, due in large measure to uptake by the liver. The present study has confirmed that in patients with Wilson's disease, the 'plasma disappearance of ${ }^{64} \mathrm{Cu}$ is measurably slower, apparently due to an impaired rate of uptake by the Wilsonian liver.

In attempting to understand the abnormality of copper transport in Wilson's disease, it is important to consider the limitations of the present data. It was not possible to determine the proportion of the injected ${ }^{64} \mathrm{Cu}$ in the liver or other body tissues at any time during the studies. However, a sequence of changes of the level of radioactivity in the liver was demonstrated by the surface counting techniques used. The patients with primary biliary cirrhosis did not differ significantly from normal subjects in this respect: the patients with Wilson's disease had a markedly different pattern of liver copper uptake. The normal plasma clearance, normal urinary excretion, and normal pattern of hepatic uptake of radiocopper in primary biliary cirrhosis, together with the absence of any other significant tissue localization of radioactivity, suggest strongly that both the liver uptake and hepatic excretory mechanisms for copper are adequate in this disease. However, in the presence of a raised pool of 'free' copper, the copper flux from plasma to liver and liver to plasma is increased. The slower but persistent rise in the liver radioactivity in Wilson's disease, together with the significantly impaired rate of plasma clearance of radiocopper, suggest both defective hepatic uptake and excretory mechanisms. The appearance of ${ }^{64} \mathrm{Cu}$-caeruloplasmin in the plasma after two to three hours was indeed deficient in Wilson's disease but we were unable to assess its quantitative importance in determining the continued accumulation of radiolabel in the Wilsonian liver. As we were unable to sample bile, liver, or other tissues apart from plasma at different times after the intravenous injection of ${ }^{64} \mathrm{Cu}$, a complete kinetic analysis of copper transport in normal subjects and in patients with Wilsonian and non-Wilsonian cirrhosis was not possible. Despite these shortcomings, we have confirmed that there is a significant abnormality in the transport of copper by the liver in patients with Wilson's disease.

It is unlikely that the impaired uptake of copper 
in Wilson's disease is due to liver damage per se, insofar as the plasma clearance and hepatic uptake of radioactivity is unimpaired in patients with other forms of liver disease. The observation that there is some improvement in the rate of hepatic copper uptake after 'decoppering' patients with Wilson's disease by prolonged penicillamine therapy has led to the proposal that the impaired liver copper uptake is primarily an expression of the high liver copper concentration (Osborn and Walshe, 1967). In the present study, we have had an opportunity to examine this hypothesis critically.

Our data indicate that the handling of intravenously injected radiocopper was abnormal even in Wilson's disease patients treated with penicillamine over prolonged periods. The fractional and absolute rates of plasma copper clearance were reduced in these patients. Unfortunately, it was not possible to estimate the liver copper concentrations in three of the patients as there was no clinical indication for a liver biopsy at the time of the study. However, it is unlikely that the liver copper concentrations in these patients would have been appreciably greater than in the group of patients with primary biliary cirrhosis (367-714 $\mu \mathrm{g} / \mathrm{g}$ dry liver) in view of their long-term 'decoppering' therapy with penicillamine. The fractional rate of plasma copper clearance was normal in the primary biliary cirrhotic patients, and, in view of their expanded 'free' plasma copper pool, the absolute rate of copper clearance was raised. It is clear that the impaired clearance of plasma copper in Wilson's disease cannot be attributed directly to the raised liver copper concentrations.

It is possible that differences in the sites of storage of copper in the liver in Wilson's disease and in primary biliary cirrhosis could profoundly alter the liver copper concentration/liver copper uptake relation. The sites of copper deposition in primary biliary cirrhosis are at present undetermined. Goldfischer and Sternlieb (1968) have demonstrated that the localization of copper in hepatocytes of patients with Wilson's disease varies with the stage of the disease. Early, when fatty changes predominate, copper is diffuse in the cytoplasm of the hepatocytes. When hepatocellular necrosis appears, this pattern persists in some nodules, while in others in the same specimen the copper stain is concentrated in granules. Later when fibrosis and cirrhosis are the predominant histopathological features, the metal is stained mainly within the lysosomes of hepatocytes. Correlation of these copper staining patterns with histopathological observations suggested that the diffuse cytoplasmic distribution may lead to cellular damage and necrosis, while copper localized to lysosomes may be less toxic.

It appears that the physiological mechanism for hepatic copper uptake is by way of the lysosomes: Goldfischer and Sternlieb (1968) have observed this phenomenon in neonatal liver and it has been noted in rats and mice where experimentally induced hepatic copper deposits generally do not produce necrosis (Goldfischer, 1967; Barka, Scheuer, Schaffner, and Popper, 1964; Lindquist, 1967; Scheuer, Thorpe, and Marriott, 1967; Verity, Gambell, Reith, and Brown, 1967). It is possible that delayed uptake of copper by the lysosomes in Wilson's disease may account for the present observations and for the toxic effects of the metal.

On the basis of the impaired hepatic uptake of radiocopper by patients with Wilson's disease, Walshe and his coworkers have suggested a diagnostic test for Wilson's disease in which the radioactivity over the liver is compared with that over a 'neutral' area, the thigh, at a given time after the intravenous injection of ${ }^{64} \mathrm{Cu}$ (Osborn and Walshe, 1964). Its prime usefulness was conceived to be in differentiating presymptomatic homozygotes from heterozygotes. More recently, Levi and Williams (1968) failed to confirm that the test was of any value in distinguishing between these two groups of patients. It should be pointed out that the present data, whilst confirming the abnormal hepatic uptake of copper in patients with Wilson's disease, are not directly comparable to these liver/thigh ratio studies. Whereas we have measured the sequential changes in radioactivity over each liver and drawn quantitative inferences from ancillary data in the same patient, the measurement of the liver/thigh ratio involves a between-patient comparison. Clearly, the surface counting characteristics could vary significantly between patients-depending upon the size, shape, and position of the liver. It is probable that these sources of measuring error account in large part for the differing results in the two studies discussed. Studies using the whole body counter to determine the body retention of copper appear to be more satisfactory in distinguishing between heterozygous carriers and homozygous normal individuals (Hamamoto et al, 1968; O'Reilly et al, 1969).

The present study has indicated a defect in copper transport in the Wilsonian liver not attributable to the cirrhotic process or to the high liver copper concentration. The precise nature of this defect remains to be elucidated. Fortunately, a new experimental model system may be provided by the foetal or neonatal liver as present evidence suggests that the foetus and the patient with Wilson's disease may have features in common with respect to copper transport (Mearrick and Mistilis, 1969), and may permit a critical evaluation of the hypothesis that the primary defect in Wilson's disease is delayed copper uptake by the lysosomes. 
R. A. Smallwood was the recipient of a Wellcome research fellowship.

The technical assistance of $\mathrm{Mr} \mathrm{D}$. Sampson is gratefully acknowledged.

\section{References}

Barka, T., Scheuer, P. J., Schaffner, F., and Popper, H. (1964)。 Structural changes of liver cells in copper intoxication. Arch. Path., 78, 331-349.

Cumings, J. N. (1959). Heavy Metals and the Brain. Thomas, Springfield, Illinois; Blackwell, Oxford.

Goldfischer, S. (1967). Demonstration of copper and acid phosphatase activity in hepatocyte lysosomes in experimental copper toxicity. Nature (Lond.), 215, 74-75.

Goldfisher, S., and Sternlieb, I. (1968). Changes in the distribution of hepatic copper in relation to the progression of Wilson's disease (hepatolenticular degeneration). Amer. J. Pathol., $53,883-900$.

Hamamoto, K., Tauxe, W. N., Novak, L. P., and Goldstein, N. P. (1968). Use of whole-body counter to study body retention of radiocopper in Wilson's disease. J. Lab. Clin. Med., 72 , 754-759.

Lindquist, R. R. (1967). Studies on the pathogenesis of hepatolenticular degeneration. I. Acid phosphatase activity in copper-loaded rat livers. Amer. J. Path., 51, 471-481.

Levi, A. J., and Williams, H. S. (1968). The liver/thigh ${ }^{\circ} \mathrm{Cu}$ ratio in Wilson's disease. Clin. Sci., 34, 379-383.

Mearrick, P. T., and Mistilis, S. P. (1969). Excretion of radio-copper by the neonatal rat. J. Lab. clin. Med., 74, 421-426.
O'Reilly, S., Weber, P., Pollycove, M., and Shipley, L. (1969). Detection of the heterozygote of Wilson's diease. J. nucl. Med., 10, 143-144.

Osborn, S. B., and Walshe, J. M. (1961). Copper uptake by the liver: study of a Wilson's disease family. In Wilson's Disease: Some Current Concepts, edited by J. M. Walshe and J. N. Cumings, pp. 141-150. Blackwell, Oxford.

Osborn, S. B., and Walshe, J. M. (1964). Studies with radiocopper $\left({ }^{\circ} \mathrm{Cu}\right)$ in Wilson's disease: the liver/thigh ratio. Clin. Sci., 27, 319-328.

Osborn, S. B., and Walshe, J. M. (1967). Studies with radioactive copper (" $\mathrm{Cu}$ and ${ }^{\circ 7} \mathrm{Cu}$ ) in relation to the natural history of Wilson's disease. Lancet, 1, 346-350.

Sass-Kortsak, A., Glatt, B. S., Cherniak, M., and Cederlund, I. (1961). Observations on copper metabolism in homozygotes and heterozygotes of Wilson's disease. In Wilson's Disease: Some Current Concepts, edited by J. M. Walshe and J. N. Cumings, pp. 151-177, Blackwell, Oxford.

Sass-Kortsak, A. (1965). Copper Metabolism. In Advanc. in clin. Chem., 8, 1-67.

Scheuer, P. J., Thorpe, M. E. C., and Marriott, P. (1967). A method for the demonstration of copper under the electron microscope. J. Histochem. Cytochem., 15, 300-301.

Smallwood, R. A., Williams, H. S., Rosenoer, V. M., and Sherlock, S. (1968). Liver copper levels in liver disease. Studies using neutron activation analysis. Lancet, $2,1310-1313$.

Sternlieb, I., and Scheinberg, I. H. (1968). Prevention of Wilson's disease in asymptomatic patients. New Engl. J. Med., 278, 352-359.

Todd, A. P., Thorpe, M. E. C., and Rosenoer, V. M. (1967). Tissue copper determinations by neutron activation analysis. $J$. clin. Path., 20, 276-279.

Walshe, J. M. (1963). Penicillamine. Practitioner, 191, 789-795.

Verity, M. A., Gambell, J. K., Reith, A. R., and Brown, W. J. (1967) Subcellular distribution and enzyme changes following subacute copper intoxication. Lab. Invest., 16, 580-590. 